\title{
Supplemental Figures
}
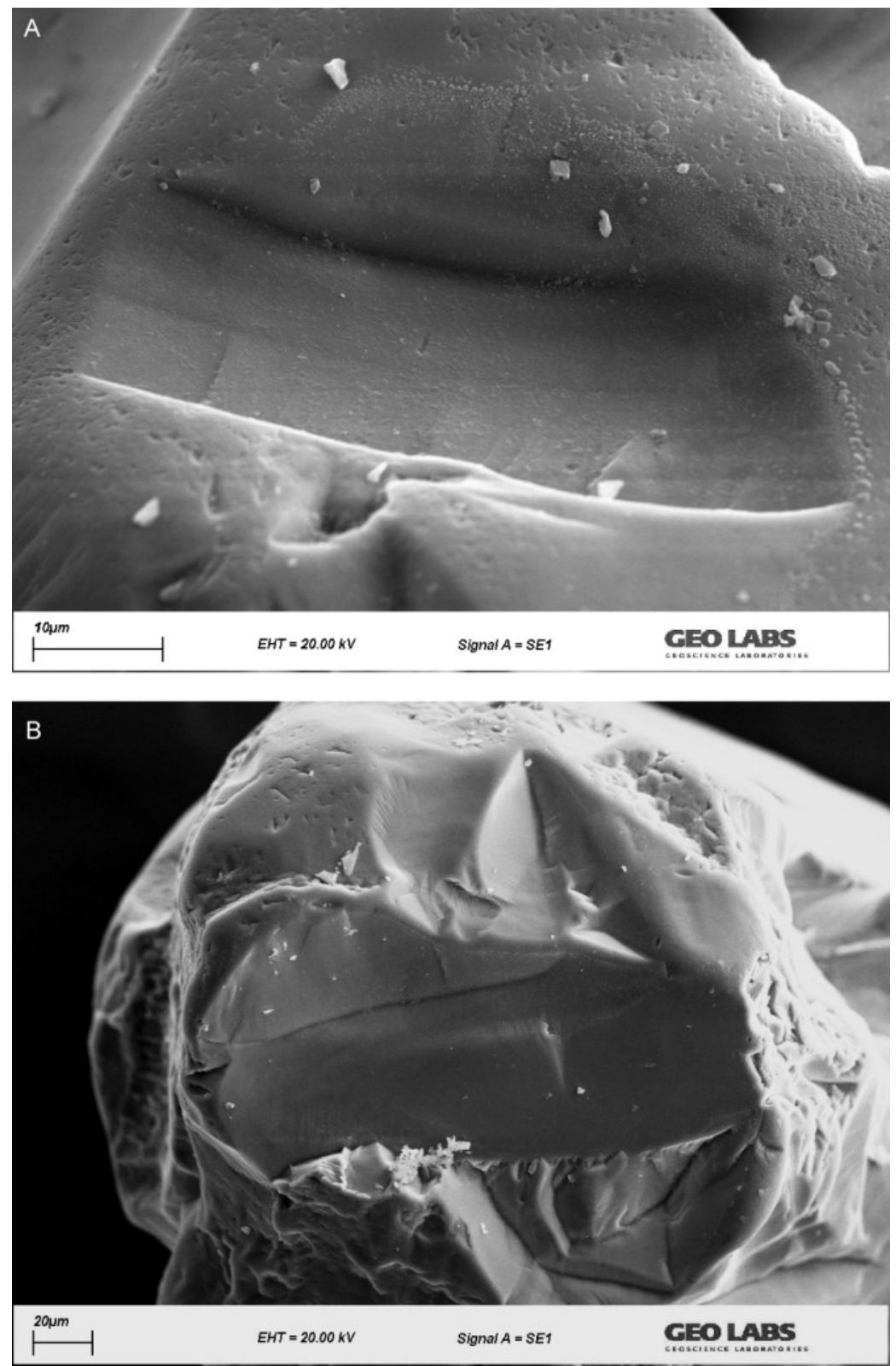

Figure DR1. Troughs with flat floor interpreted as resulting from grinding and scouring under the persistent overburden pressures from glaciers. A: In a flat surface of a quartz grain. B: Cutting through an edge of a quartz grain. 

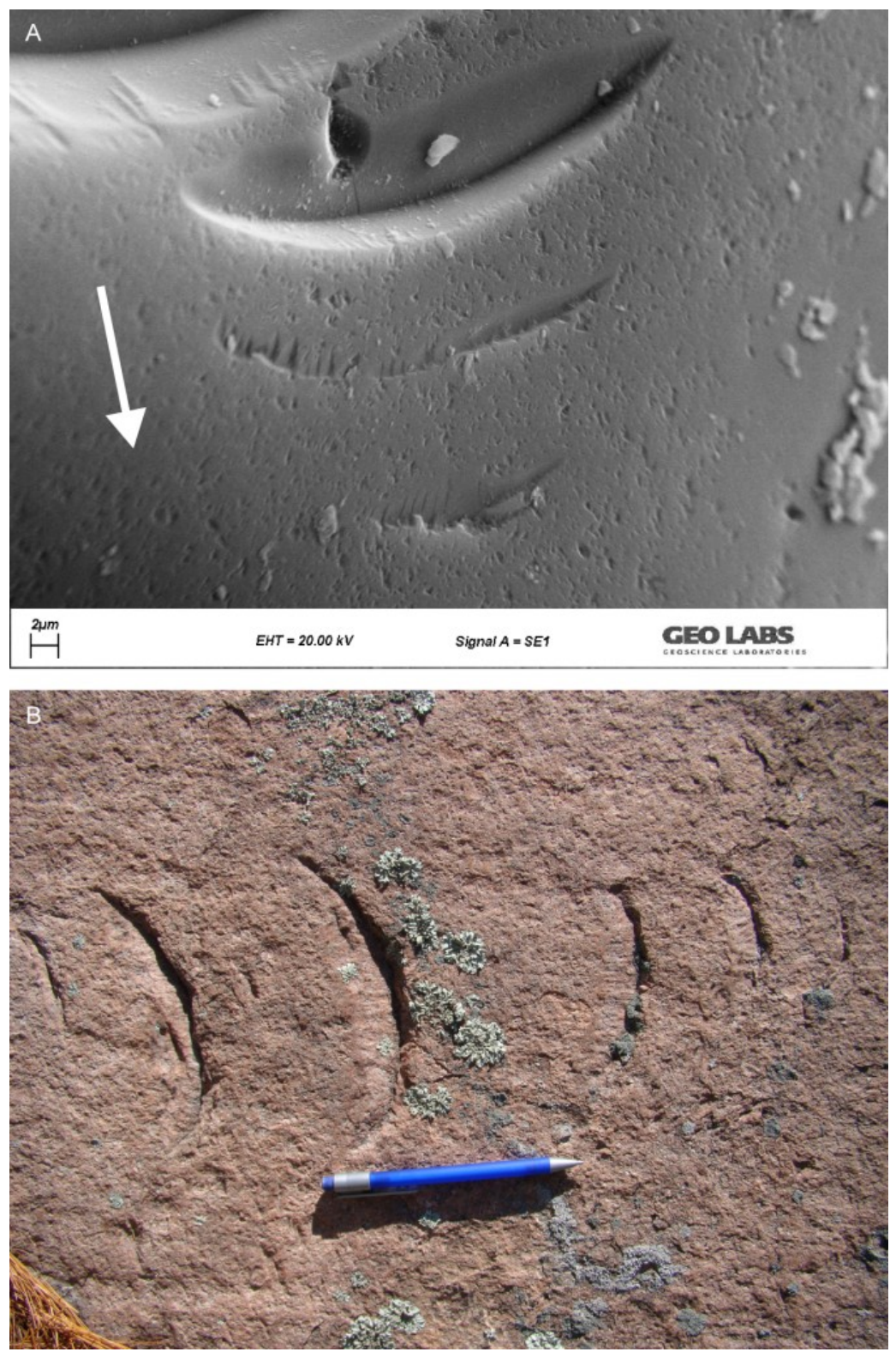

Figure DR2. Trails of crescentic gouges resulting from subglacial fracturing and gouging by rock fragments that were frozen to the sole of a glacier and moved in a stick-slip fashion under the persistent overburden pressures. A: Those on a quartz grain from the Pliocene till. B: Those produced by the Late-Wisconsinan Laurentide Ice Sheet on granite bedrock in northern Ontario. Arrow and pen (15 cm long) point to ice flow direction. 


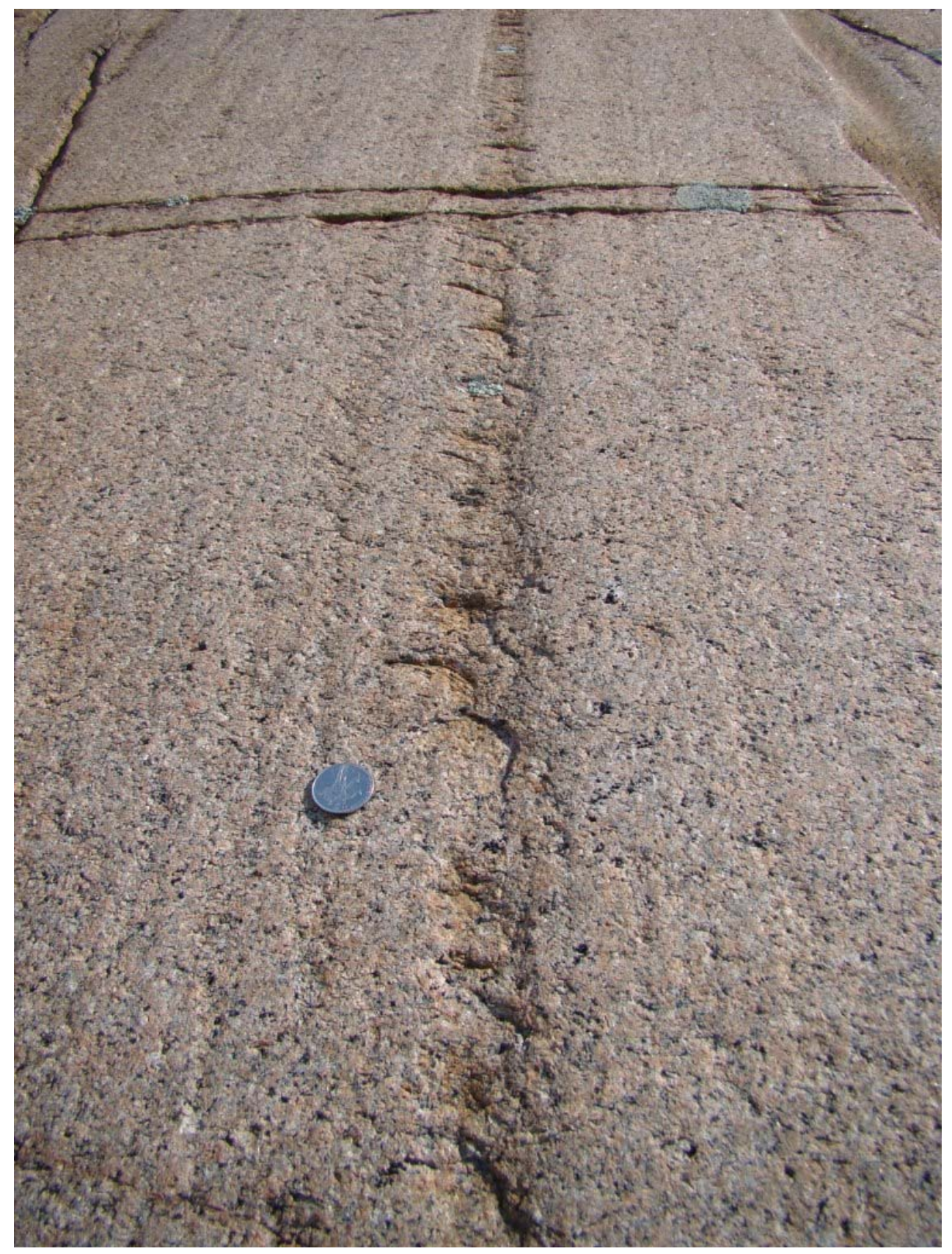

Figure DR3. Coaxial crescentic gouges in a groove produced by the Late-Wisconsinan Laurentide Ice Sheet on granite bedrock in northern Ontario. Ice flow direction from bottom to top. Coin $2.3 \mathrm{~cm}$ in diameter. Compare Figs. 3B and 3C in the main text with these features. 


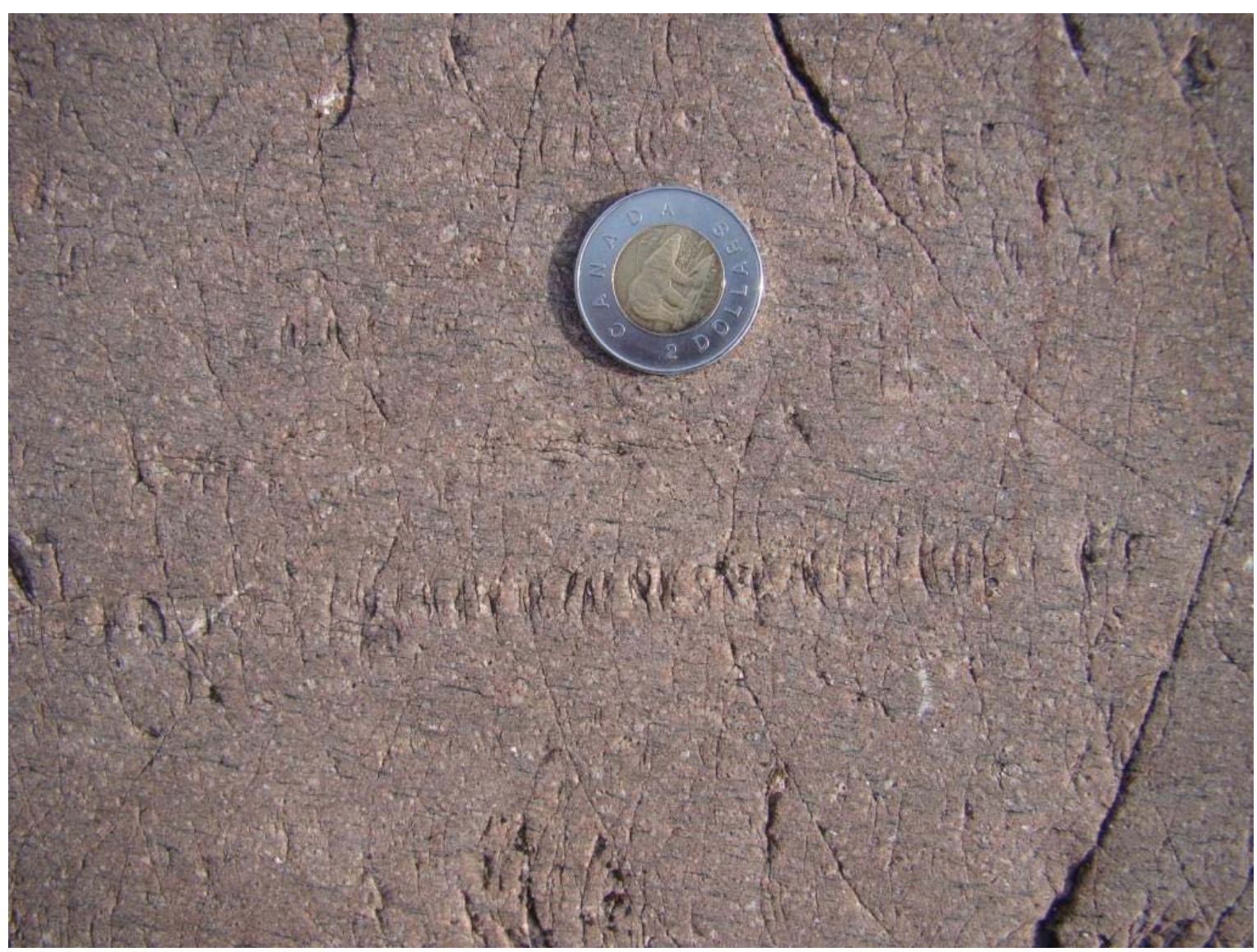

Figure DR4. Transverse crescentic fractures along striae produced by the Late-Wisconsinan Laurentide Ice Sheet on granite bedrock in northern Ontario. Ice flow direction from left to right. Coin $2.7 \mathrm{~cm}$ in diameter. Compare Fig. 3D in the main text with these features. 

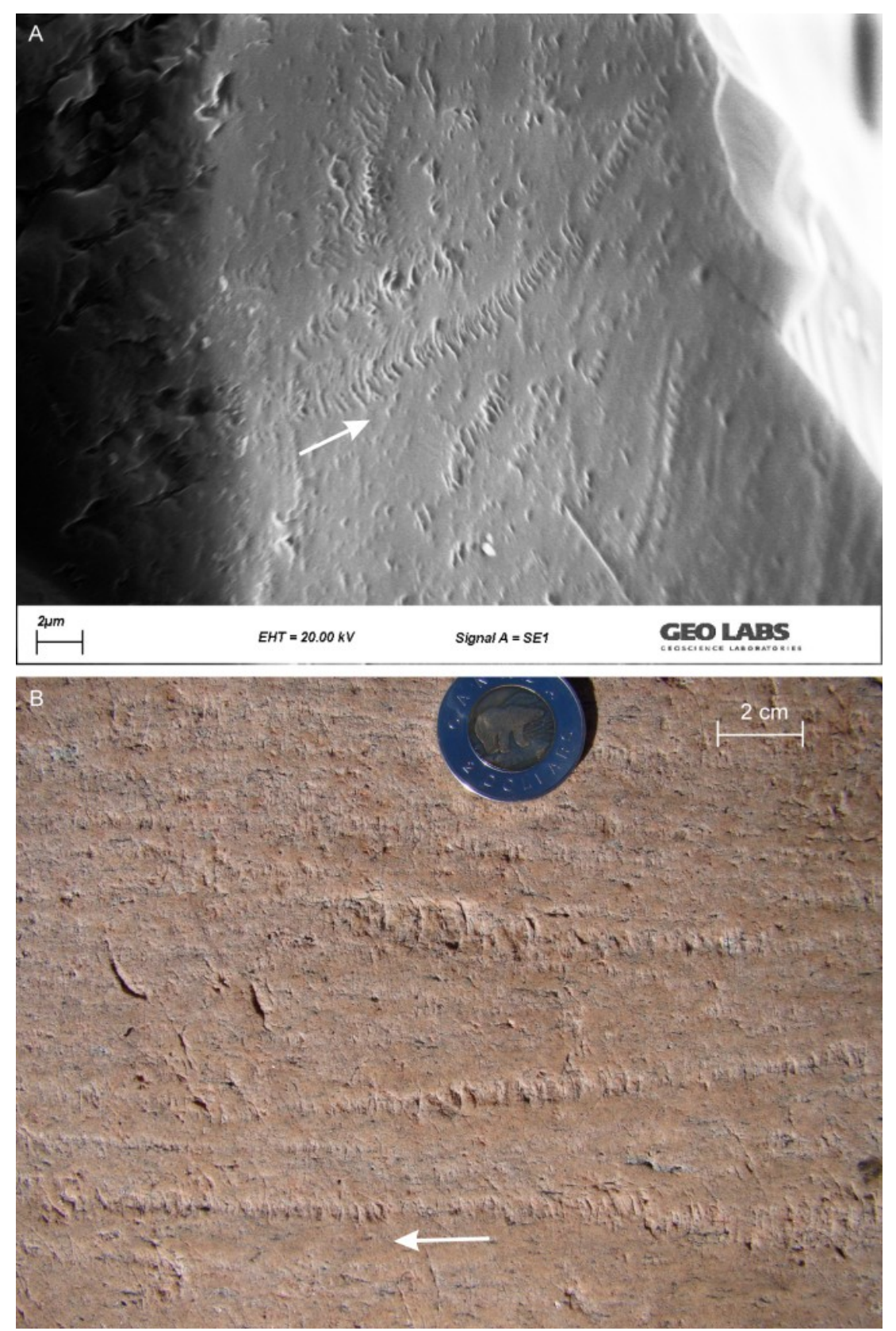

Figure DR5. Transverse crescentic fractures along striae resulting from subglacial grinding and fracturing under the persistent overburden pressures from glaciers. Arrows indicate ice flow directions. A: Those on a quartz grain from the Pliocene till. B: Those produced by the LateWisconsinan Laurentide Ice Sheet on granite bedrock in northern Ontario. Note that (A) is the close-up view of Fig. 3D of the main text. 